\title{
Utility of early postoperative MRI in hindbrain-related syringomyelia. A preliminary prospective study on five patients
}

\author{
Pierpaolo Lunardi ${ }^{1}$, Luciano Mastronardi ${ }^{1}$, Jibril Osman Farah ${ }^{1}$, Claudio Di Biasi ${ }^{2}$, Guido Trasimeni ${ }^{2}$, Fabrizio \\ Puzzilli $^{1}$ and Aldo Fortuna ${ }^{1}$ \\ ${ }^{1}$ University 'La Sapienza' - Department of Neurological Sciences, Neurosurgery and ${ }^{2} 1$ st Medical Clinic, CT-MR \\ Unit, Rome Italy
}

\begin{abstract}
We report a series of five patients operated on for hindbrain-related syringomyelia with posterior fossa decompression and duraplasty. In all cases an early postoperative MRI was performed (24-36 h after surgery). These images have been compared with the preoperative ones and with those obtained, 1, 3 and 6 months after operation. Both before and after surgery there was not always a tight correlation between clinical and MRI pictures. In all but one patient the early postoperative MR images showed a reduction of syrinx size and were as to those obtained later. We discuss the results observed in our small series and analyze the role of early postoperative MRI studies in patients with hindbrain-related syringomyelia.
\end{abstract}

Keywords: hindbrain hernia; magnetic resonance imaging; posterior fossa decompression; syringomyelia

\section{Introduction}

The term syringomyelia was introduced to indicate a tubular dilatation of the central canal of the spinal cord. ${ }^{1}$ At present, the term describes the presence of a cystic cavity within the spinal cord, containing fluid identical to CSF. ${ }^{2}$ Along with the development of diagnostic tools, it has been becoming clear that syringomyelia is not a single nosographic entity but a disorder with several possible causes. ${ }^{2-5}$ Syringomyelia associated with abnormalities of the craniovertebral junction ('hind-brain related' syringomyelia) is the most frequent variety (about $73 \%$ of patients), especially the adult-type, that is the syringomyeliaChiari I malformation. ${ }^{3-5}$ A syrinx is present in about $75 \%$ of patients with the Chiari Type I deformity, and in about $88 \%$ of those with the Chiari Type II. ${ }^{\circ}$

Among the several etio-pathogenetic theories formulated up to the present time to explain the Chiarisyringomyelia complex, the most persuasive are the hydronamic one proposed by Gardner, ${ }^{7}$ and the dissociation of cranial and spinal CSF pressure proposed by Williams. ${ }^{3-5}$ Recently, with the help of the phase-contrast and phase-contrast cine MR and of the intraoperative ultrasonography, Oldfield et $a l^{8}$ observed that the progression of the syrinx appears to be related to movements of CSF across an obstructed foramen magnum during the cardiac cycle (downward movement of the syrinx fluid during systole and upward movement during diastole).

Correspondence: L Mastronardi, M.D., Ph.D.
In recent years MRI permits verification of the results obtained with and without the several surgical techniques that are available for the various types of syringomyelia, included the hind-brain related form. Some authors have reported the results of postoperative MRI, ${ }^{9-13}$ but we have not been able to find any paper which reports the value of early postoperative MRI in predicting the surgical outcome of these patients.

The aim of our prospective study has been to quantify with an early postoperative MRI $(24-36 \mathrm{~h}$ after surgery) the amount of reduction of the cyst size immediately after foramen magnum decompression (FMD) and to compare the early images with that obtained after 1, 3 and 6 months.

\section{Patients material and methods}

The clinical features of five consecutive patients operated on for hindbrain-related syringomyelia are summarized in Table 1.

Two patients had been operated on previously in another Neurosurgical Center, 6 months (Case 4) and 9 years before (Case 5), with a syringosubarachnoid shunt and a syringoperitoneal shunt, respectively. In Case 4 the patient had not observed any change of symptoms. In Case 5, the clinical picture remained unchanged for 6 years and worsened during the last 3 years; a pre-reoperative spinal MRI showed an enlargement of the superior pole of syrinx.

In all cases a small suboccipital craniectomy (about 
Table 1 Summary of five patients with hindbrain-related syringomyelia

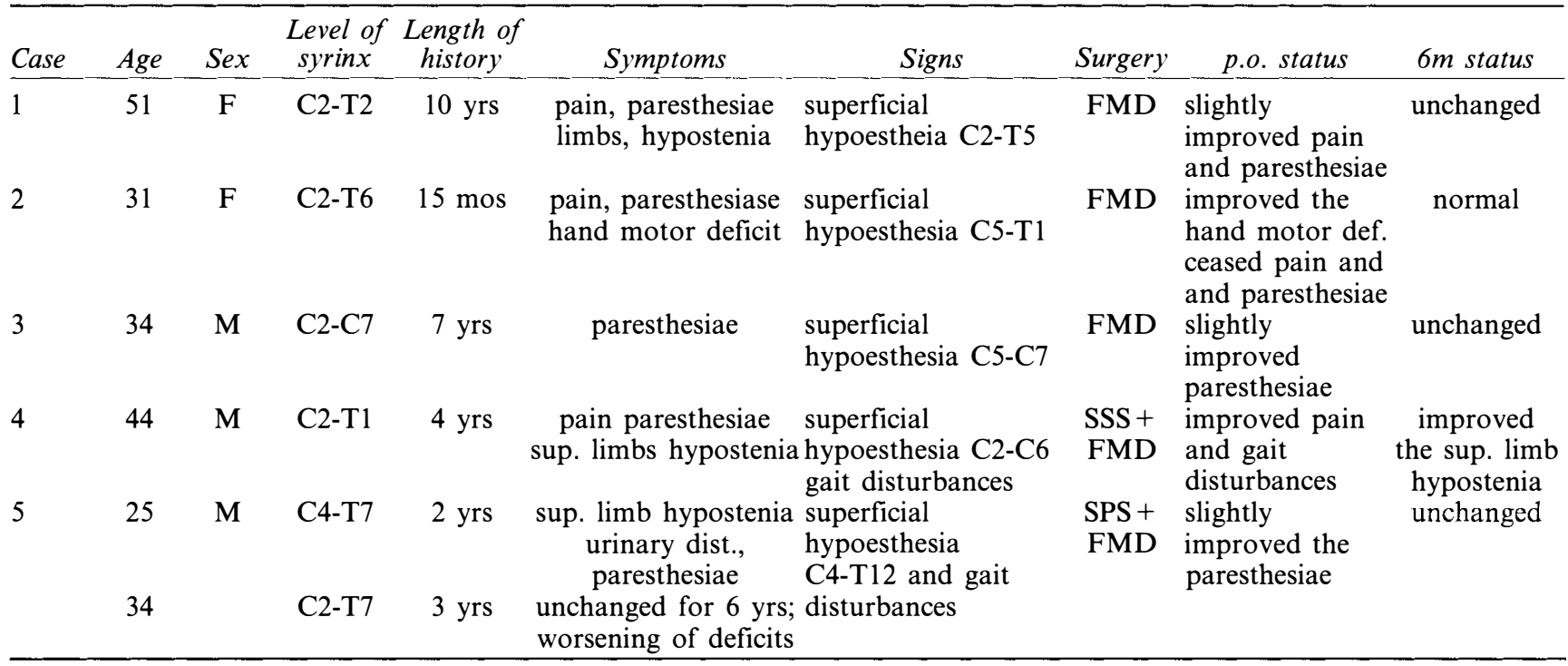

p.o. status = neurological picture on discharge; $6 \mathrm{~m}=$ six-month; $F M D=$ foramen magnum decompression; SSS $=$ syringosubarachnoid shunt; SPS = syringo-peritoneal shunt; def. = deficit; dist. = disturbances; sup. = superior

$3 \times 3 \mathrm{~cm}$ ), an upper cervical laminectomy ( $\mathrm{C} 1$ or $\mathrm{Cl}$ $\mathrm{C} 2$ ), and a duraplasty were performed. ${ }^{2,14}$ The arachnoid was not opened.

In all patients a spinal MRI was performed 24$36 \mathrm{~h}$ after surgery. It was impossible to obtain the examination within the first $24 \mathrm{~h}$ because patients experienced pain at the level of the wound. A followup MR study and a clinical assessment were performed 1, 3 and 6 months after surgery.

In order to evaluate the clinical outcome, we compared the neurological examination with that obtained on admission. The variations of syrinx size on MRI have been calculated using the Alteration-rate (A-rate) index, ${ }^{11}$ that is: postoperative area preoperative area/preoperative area $\times 100$. The area of syrinx was calculated on the basis of the values of the vertical and anterior-posterior maximum diameters. All measurements were obtained on T1weighted images, in the mid line sagittal scan, and directly from the imager; two neuroradiologists verified the data, separately and blindly. The difficulties found in aligning patients and measuring the syrinx area determined an inter-observer variation (IOV) of measurements of about $\pm 10 \%$. An A-rate ranging from -100 to -20 was considered a good result, from -20 to +20 a poor result. ${ }^{11}$

\section{Results}

The preoperative and postoperative MR features (area of cavities and A-rates) are summarized on Table 2. In three patients (Cases 1, 4 and 5) (Figure 1) the early postoperative MRI control revealed a marked reduction, and in two (Cases 2 and 3 ) as slight reduction of syrinx size. In two of three patients with a marked
Table 2 Preoperative and postoperative MRI data of five patients with hindbrain-related syringomyelia

\begin{tabular}{ccccc}
\hline & $\begin{array}{c}\text { Preoperative } \\
\text { approximate } \\
\text { area of } \\
\text { syringes } \\
\pm I O V\end{array}$ & $\begin{array}{c}\text { A-rate on } \\
\text { early } \\
\text { post- } \\
\text { operative } \\
\text { MRI }\end{array}$ & $\begin{array}{c}\text { A-rate on } 3 \\
\text { month } \\
\text { post- } \\
\text { operative } \\
\text { MRI }\end{array}$ & $\begin{array}{c}\text { A-rate on 6 } 6 \\
\text { month } \\
\text { post- } \\
\text { operative } \\
\text { MRI }\end{array}$ \\
\hline Case 1 & $10 \pm 1 \mathrm{~cm}^{2}$ & $-85 \%$ & $-75 \%$ & $-70 \%$ \\
Case 2 & $23 \pm 2 \mathrm{~cm}^{2}$ & $-15 \%$ & $-20 \%$ & $-95 \%$ \\
Case 3 & $22 \pm 2 \mathrm{~cm}^{2}$ & $-10 \%$ & $-10 \%$ & $-15 \%$ \\
Case 4 & $13 \pm 1 \mathrm{~cm}^{2}$ & $-60 \%$ & $-60 \%$ & $-60 \%$ \\
Case 5 & $11 \pm 1 \mathrm{~cm}^{2}$ & $-25 \%$ & $-30 \%$ & $-30 \%$ \\
\hline
\end{tabular}

$\mathrm{IOV}=$ inter-observer variation

postoperative reduction of cyst size only slight clinical improvement has been observed (Cases 1 and 5), whereas in the third patient (Case 4) progressive neurological improvement occurred. In Case 5 the greatest reduction of cyst size has been observed at the cranial level (portion developed in the last 3 years before second operation).

In one of the two patients with slight early postoperative reduction of syrinx size (Case 2) the clinical picture markedly improved, and 6 months after surgery the woman had only slight paresthesiae in the right hand; in the second patient (Case 3) only slight subjective improvement occurred. Better results have been observed in patients with the shortest preoperative clinical history (Cases 2 and 4).

In all but one case the MRI performed 1, 3 and 6 months after surgery showed a syrinx size substantially unchanged in comparison with that observed in the early postoperative period. In Case 2 a dramatic 


Early postoperative MRI in hindbrain syringomyelia
$\mathrm{P}$ Lunardi et al

a

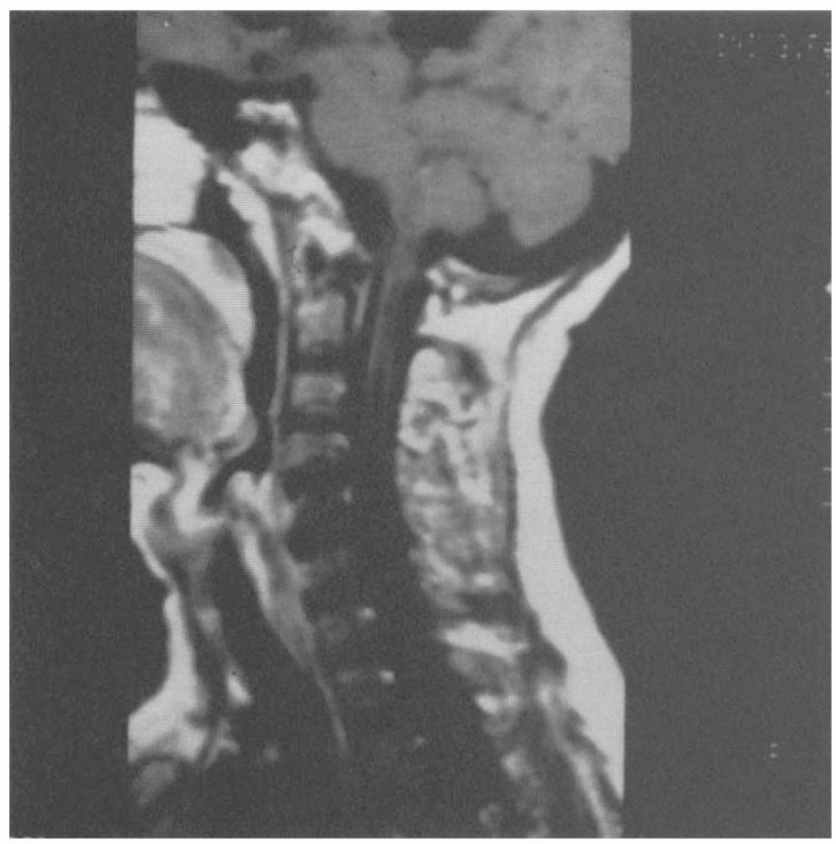

b

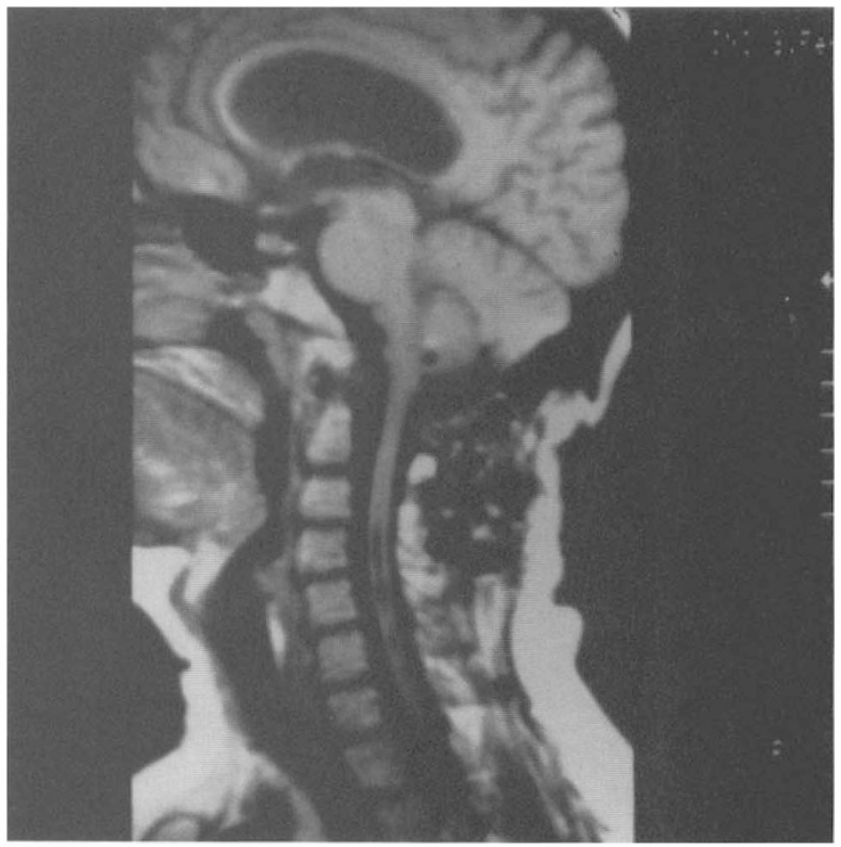

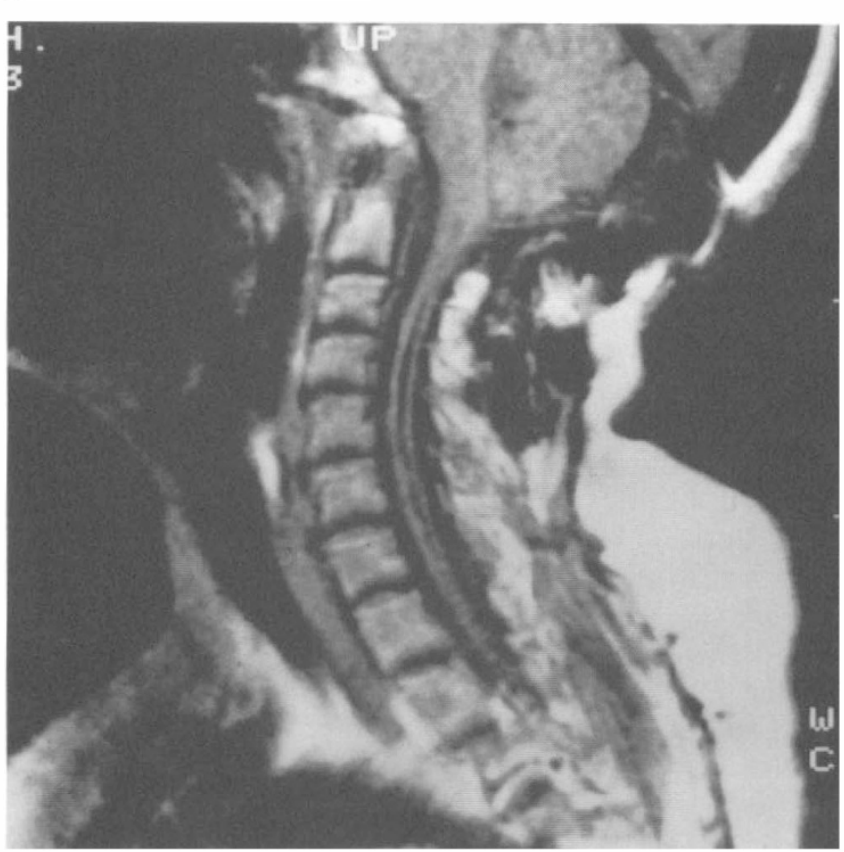

Figure 1 Case 1. (a) Preoperative median sagittal T1-weighted MRI showing syringomyelia extending from C2 to T2. (b) Early postoperative MRI ( $36 \mathrm{~h}$ after surgery) showing a marked reduction of syrinx size. (c) MRI performed 6 months after FMD revealing a substantially unchanged picture

reduction of syrinx size has been observed after only 6 months. There was not always a tight correlation between clinical and MR preoperative pictures.

\section{Discussion}

In the past few years MRI makes the diagnosis and the follow-up of patients with various types of syringomyelia easier, offering the possibility of a quantitative evaluation of spontaneous or postoperative syrinx size variations. ${ }^{11,13}$ MRI is the most sensitive examination available, revealing about one third of cavities not observed with CT. ${ }^{10} \mathrm{~T}_{1}$-weighted images provide general morphological information, while $\mathrm{T}_{2}$-weighted images inform us about the condition of pericystic spinal cord tissue and about the CSF dynamics. ${ }^{10}$ On $\mathrm{T}_{2}$-weighted images the portions of syrinx with pulsating water appear like low signal areas, whereas 
portions with stationary CSF have a high signal intensity. $9,10,12,13$

Cyst and cord size measurements are more accurate on $\mathrm{T}_{1}$-weighted images, because of the lower signal changes related to CSF flow. ${ }^{10,11}$ Fujii et al ${ }^{11}$ introduced two indices for the quantitative evaluation of preoperative and postoperative sizes of the syrinx on $\mathrm{T}_{1}$-weighted images: the syringo-cord ratio ( $\mathrm{S}-\mathrm{C}$ ratio) and the Alteration rate (A-rate). The first calculates the percentage of syrinx area in the spinal cord in the median sagittal image, and the second the percentage of variation of cyst area following surgery. In their series, Fujii et al ${ }^{11}$ reported that more than $85 \%$ of cases had an excellent or a good A-rate (from -20 to -100$)$ and concluded that the improvement of symptoms is closely related to shrinkage of syrinx. ${ }^{11}$

On evaluating the postoperative outcome by MRI (6 months and 1 year after surgery), Vaquero et al ${ }^{13}$ affirmed that syringo-subarachnoid shunt and FMD are equally useful to obtain syrinx collapse. On reporting their experience on postoperative $\mathrm{MR}$ studies of syringomyelia, Barkovich et $a l^{9}$ stressed the importance of the flow void within the cysts in evaluating the response to surgery. In fact, the lack of signal within the cavities on $\mathrm{T}_{2}$-weighted images is related to the pulsatile flow of water, described as 'sloshing' by Williams; ${ }^{3-5}$ the persistence of flow void after surgery means that the syrinx is not adequately treated. ${ }^{9}$

Prolonged follow-up frequently disclosed slow progression or stabilization of symptoms, even in patients with good surgical results verified with MRI. ${ }^{12}$ In fact, even those patients who obtain a clinical and/or radiological improvement with operation may later experience symptomatic recurrence or slow progressive deterioration. ${ }^{15}$ In serial postoperative MRI controls performed at varying intervals, Oldfield $e t a l^{8}$ observed a collapse of cysts within $1-6$ months after surgery contemporary to clinical improvement or stabilization. Analyzing the postoperative clinical assessment at 6 weeks, 4 months and yearly, Milhorat et $a l^{16}$ observed that $83 \%$ of patients improved, $13 \%$ were unchanged and $2 \%$ were worse.

In the available literature no-one has specified when it is best to perform the first postoperative MRI, in order to evaluate the radiological outcome of hindbrain-related syringomyelia. Three of seven patients reported by Oldfield et $a l^{8}$ had a postoperative MR 5-7 days after surgery: in the first patient the syrinx size did not change immediately, but progressively disappeared after 3 months; in the second patient the cavity decreased at once, but did not change after 6 and 18 months; and in the third patient the syrinx decreased at once and disappeared after 14 months.

By our knowledge, the present study represents the first attempt to evaluate the usefulness of MRI in the early postoperative period, with the aim of examining the precocious variations of syrinx size after FMD. At the last follow-up 6 months after surgery, the best clinical-radiological results have been observed in Cases 2 and 4, whose preoperative clinical history was the shortest; patient 1 had a good early, 3 and 6month MRI result, but a poor early and late clinical result. The reduction of syrinx area in the early postoperative MRI control can be considered good ${ }^{11}$ in patients 1, 4 and 5 (Figure 1) and poor in patients 2 and 3. One of the last two patients (Case 2) showed a marked clinical and MRI improvement 6 months after surgery, whereas the second patient (Case 3) had only subjective improvement. Notwithstanding the marked early postoperative reduction of cyst size, in patient 4 slow and progressive neurological improvement occurred, whereas in patients 1 and 5 only slight clinical improvement has been observed; moreover, in patient 5 the reduction of syrinx size was most marked in the upper portion of the cyst (increased during the last 3 years before re-operation). Thus, even if a good or an excellent A-rate has been observed in three of five patients in an early postoperative MRI and in four of five in a late MRI, only two patients (Case 2 and 4) had good improvement of neurological deficits.

These observations confirm that there is not always a close correlation between the syrinx area and the severity of clinical picture. Therefore, even if Fujii et $a l^{11}$ concluded that the postoperative reduction of syrinx size could be in direct relation with any improvement of neurological status, we agree with others $^{13,17,18}$ that in syringomyelic subjects the size of syrinx cannot be strictly related to the nature, the distribution and the severity of the clinical symptoms and signs, both before and subsequent to surgery.

The results observed in our small series suggest two considerations: (a) an early postoperative MRI showed in all but one patient a picture substantially equal to that performed after 1, 3 and 6 months, indicating that if a reduction of syrinx size has been obtained with FMD this could often be observed 24-36 h after surgery; (b) in those patients in which the early postoperative MRI showed a marked reduction of syrinx size (A-rate $>-20 \%$ ), it is presumed that before surgical decompression a high intracavity tension existed. Thus, like hydrocephalus, some syringomyelic cavities could be considered 'hypertensive' and others 'normotensive'. In patient number 2 the reduction of syrinx size observed only 6 months after surgery presumably indicates that the preoperative intracavity tension was low and then, the FMD slowly re-established the normal CSF pathway. On the other hand high preoperative intracavity tension could justify the marked shrinkage of syrinx observed in the early postoperative MRI in patients numbers 1 and 4 .

In conclusion, even if our preliminary considerations are to be confirmed by larger prospective trials, we believe that in patients operated on for a hindbrain-related syringomyelia early postoperative MRI control could be useful, disclosing at once the degree of cyst size reduction. In fact, it is possible that in a percentage of patients the MRI obtained 1,3 or 6 
months after operation could show a picture substantially equal to that performed during the first $24-36 \mathrm{~h}$ after operation.

\section{References}

1 Ollivier d'Angers CP. Traite de la moelle epiniere et de ses maladies. Chez Crevot: Paris 1827, pp 178-183.

2 Batzdorf U. Syringomyelia related to abnormalities at the level of the craniovertebral junction. In: Batzdorf U.(ed). Syringomyelia: current concepts in diagnosis and treatment. William \& Wilkins: Baltimore, 1991, pp 163-182.

3 Williams B. Progress in syringomyelia. Neurol Res 1986; 8: $130-$ 145.

4 Williams B. Pathogenesis of syringomyelia. In: Batzdorf U. (ed). Syringomyelia: current concepts in diagnosis and treatment. William \& Wilkins: Baltimore, 1991, pp 59-90.

5 Williams B. Surgery for hindbrain related syringomyelia. In: Symon L et al (eds). Adv Tech Stand Neurosurg 20. SpringerVerlag: Wien-New York, 1993, pp 107-164.

6 Oakes WJ. Chiari malformations, hydromyelia, syringomyelia. In: Wilkins RH, Rengachary SS (eds). Neurosurgery. McGrawHill: New York, 1985, pp 2102-2124.

7 Gardner WJ, Angel J. The mechanism of syringomyelia and its surgical correction. Clin Neurosurg 1959; 6: 131-140.

8 Oldfield EH, Muraszko K, Shawker TH, Patronas NJ. Pathophysiology of syringomyelia with Chiari I malformation of the cerebellar tonsils. Implications for diagnosis and treatment. J Neurosurg 1994; 80: 3-15.
9 Barkovich AJ, Sherman JL, Citrin CM, Wippold II FJ. MR of postoperative syringomyelia. AJNR 1987; 8: 319-327.

10 Enzmann DR. Imaging of syringomyelia. In: Batzdorf U. (ed). Syringomyelia: current concepts in diagnosis and treatment. William \& Wilkins: Baltimore, 1991, pp 116-139.

11 Fujii K, Natori Y, Nakagaki H, Fukui M. Management of syringomyelia associated with Chiari malformation: comparative study of syrinx size and symptoms by magnetic resonace imaging. Surg Neurol 1991; 36: $281-285$.

12 Matsumoto T, Symon L. Surgical management of syringomyelia. Current results. Surg Neurol 1989; 32: 258-265.

13 Vaquero J, Martinez R, Arias A. Syringomyelia-Chiari complex: magnetic resonance imaging and clinical evaluation of surgical treatment. J Neurosurg 1991; 73: 64-68.

14 Batzdorf U. Chiari I malformation with syringomyelia. Evaluation of surgical therapy by magnetic resonance imaging. $J$ Neurosurg 1988; 68: 726-730.

15 Ventureyra ECG, Higgins MJ. Syringomyelia and the Chiari type I malformation: new pathophysiologic concepts. Crit Rev Neurosurg 1994; 4: 275-285.

16 Milhorat TH et al. Surgical treatment of syringomyelia based on magnetic resonance imaging criteria. Neurosurgery 1992; 31: $231-245$.

17 Arias A, Millàn I, Vaquero J. Clinico-morphological correlation in syringomyelia: a statistical study assisted by computer measurement of magnetic resonance images. Acta Neurochir 1991; 111: 35-39.

18 Grant $\mathrm{R}$ et al. Syringomyelia: cyst measurement by magnetic resonance imaging and comparison with symptoms, signs and disability. J Neurol Neurosurg Psychiatry 1987; 50: 1008-1014. 